\title{
Association of Lower Lumbar Facet Joint Osteoarthritis With Demographic Factors And Intervertebral Disc Degeneration In Patients With Low Back Pain
}

\author{
Haider N. Al-Tameemi and Farah Hikmet Majid
}

\begin{abstract}
Background: Facet joint osteoarthritis (FJO) is an important element of lumbosacral degenerative disease. However, its association with other possible risk factors is still controversial. This study was conducted to investigate the association of FJO with risk factors and with presence of lumbar intervertebral disc degeneration (IVDD).

Patient and method: Lumbosacral magnetic resonance imaging (MRI) examinations of 100 patients (36 male and 64 female) with low back pain (LBP) were reviewed in this crosssectional retrospective study for the presence of FJO. The overall prevalence of FJO as well as the number of levels affected was correlated with the age, gender, body weight, height, BMI, female parity. FJO was also correlated with presence of corresponding IVDD.
\end{abstract}

Results: Overall prevalence of FJO was $23 \%$. The prevalence of FJO was significantly associated with advancing age $(p=0.018)$. Females were more affected than males but without statistical significance ( $p$ value $=0.79$ ). Similarly, FJO were more frequent in women with advanced multiparity but the association was statistically not significant ( $p$ value 0.1 ) there was statistically significant association between BMI and number of levels affected by FJO (p value 0.037 ). IVDD was significantly associated with higher prevalence of FJO especially at $L 3 / 4$ and $L 4 / 5$ levels ( $p$ values $P<0.0001$ and 0.04 respectively).

Conclusion: Age was the single most important factor significantly associated with both overall higher prevalence of FJO and higher number of involved levels. BMI was statistically associated with increasing number of level affected. IVDD was significantly associated with presence of FJO at L3/4 \& L4/5 levels.

Index Terms-facet joints, osteoarthritis, magnetic resonance imaging.

\section{INTRODUCTION}

Low back pain (LBP) is considered as one of the commonest complains encountered in the primary care and majority of people will have some sort of LBP during their lives resulting in significant morbidity, disability and reduced productivity $[1,2]$.

LBP have different causes, with lumbosacral spinal degenerative disease being amongst the common ones which is manifested in form of intervertebral disc degeneration (IVDD), ligamnetum flavum (LF) thickening and facet joint osteoarthritis (FJO) in variable degrees of severity and combinations. Both computerized tomography (CT) and magnetic resonance imaging (MRI) can demonstrate variable features of FJO with good agreement between both

Published on April 01, 2020.

Haider N. Al-Tameemi, Faculty of Medicine, University of Kufa, Iraq (email: haidern.altameemi@uokufa.edu.iq)

Farah Hikmet Majid, Faculty of Medicine, University of Kufa, Iraq. imaging modalities, although MRI has the advantage of being safe regarding radiation hazard rendering it as the first choice in evaluation such conditions $[3,4]$.

FJO has been blamed as a source of LBP for a long time, especially in old age patients $[5,6]$ because of the nature of facet joint innervation [7] and the contribution to the spinal canal stenosis and roots compression together with LF hypertrophy and disc herniation [8]. Despite that several studies were conducted, debate is still present on the exact correlation between the presence of LBP and the spinal degeneration, particularly FJO, documented on imaging modalities [9-17]

FJO, as part of more general spinal degeneration, is a multifactorial disease, however, there is a controversy on the nature of combination between facet joints hypertrophy and other forms of spinal degenerative changes and it is not well known which patient will have one or other form of degeneration. This study was conducted to assess some of possible risk factors (including age, gender, parity, weight, height, body mass index) that may predispose for development of FJO and to investigate the relationship between presence of FJO and lumbosacral IVDD in with LBP.

\section{PATIENTS AND METHOD}

This is cross-sectional study was conducted on conveniently selected 100 patients (36 male and 64 female) already referred to the MRI unit of the radiology department for evaluation of LBP. The study was approved by the Institutional Ethical Committee and no consent was taken from the patients because of the non-interventional nature of the study provided that the collected data are kept confidential and not disclosed to unauthorized personnel.

The population of the study included any patient with LBP who underwent lumbosacral MRI examination. Patients with spinal tumor, congenital deformity or trauma as well as those whose MRI examinations do not included all L3/4, L4/5 and L5/S1 levels were excluded from the study. Demographic and clinical information were taken from the record as well as directly from the patients themselves.

Imaging evaluation: Radiological evaluation of the included MRI studies was done by a board-certified radiologist (with more than 10 years experience in neuroradiology and spinal imaging). A general assessment of lumbosacral spine was done at first for any exclusion criteria and then a more dedicated evaluation of L3/4, L4/5 and L5/S1 intervertebral discs for the grade of IVD using Pfirrmann grading system [18]. Using axial T2 weighted 
images (Figure 1 and 2), facet joints were assessed for the presence of FJO at each level according to Weishaupt D et al [3]. FJO was documented to be present when grade 2 and more was seen and when asymmetry is present, the higher side was assigned for that level.

MRI examination. All patients were examined by the same MRI device (Acheiva 1.5 Tesla, Philips Medical System, 2011), using the following sequences: sagittal T1 weighted TSE $(\mathrm{TE}=8 \mathrm{~ms}, \mathrm{TR}=500 \mathrm{~ms})$, sagittal $\mathrm{T} 2$ weighted TSE $(\mathrm{TE}=100 \mathrm{~ms}, \mathrm{TR}=4000 \mathrm{~ms})$ and axial $\mathrm{T} 2$ weighted TSE ( $\mathrm{TE}=100 \mathrm{~ms}, \mathrm{TR}=4000 \mathrm{~ms}$ ). No intravenous contrast medium was administrated

Statistical analysis of the data was done using SPSS, version 2.4; IBM, USA. The cases were subdivided into two groups; those with FJO and those without FJO. Differences between the two groups regarding demographic characteristic age, gander, female parity, weight, height and body mass index (BMI) were calculated. Furthermore, prevalence and grades of DD amongst the two groups were assessed and correlated with presence of FJO at each level using Pearson correlation coefficient. $\mathrm{P}$ value of $<0.05$ was set as statistically significant.

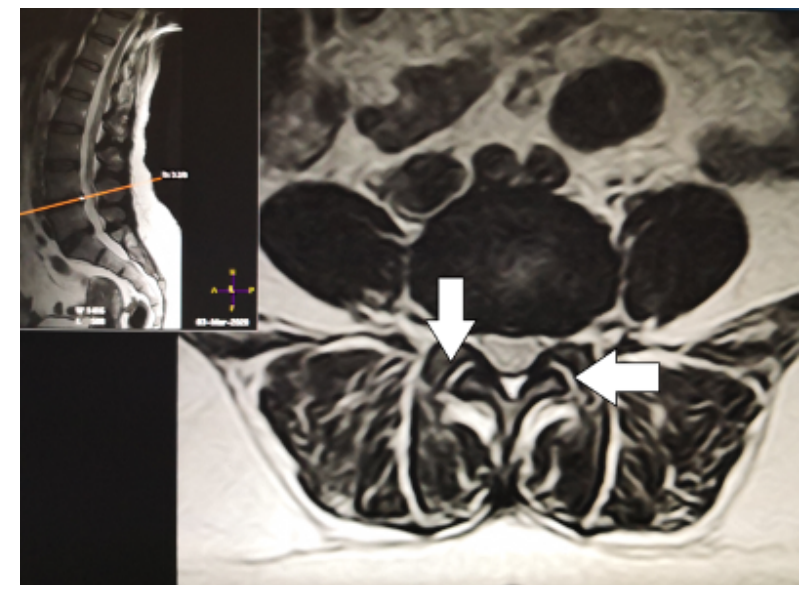

Fig. 1. Axial T2-weighted MR image at L4-5 intervertebral disc showing nor4mal bilateral facet joints evident by the normal joint space, normal high signal of the synovial fluid and normal thin lines of articular surfaces (white arrows).

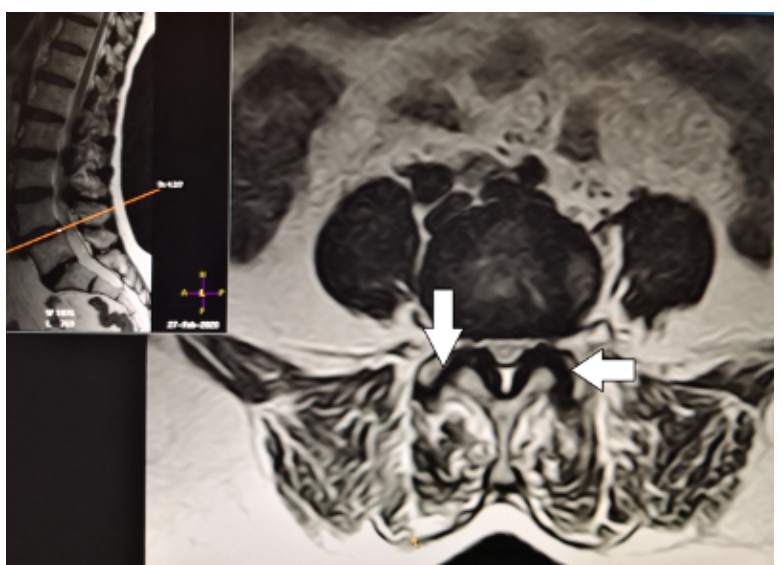

Fig. 2. Axial T2-weighted MR image at L4-5 intervertebral disc showing bilateral facet joints osteoarthritis (FJO) evident by joint space narrowing, lost high signal of the synovial fluid and sclerotic hypertrophied articular surfaces (white arrows).

\section{RESULTS}

A total of 300 IVD of 100 patients (36 male and 64 female) were studied. Mean age was $46.62 \pm 13.72$ years, with mean BMI of $30.4 \pm 5.9$. Out of 100 patients, 23 showed features of FJO (23\%), of these 11 had single level $(48 \%)$, and 6 with two and 6 with three levels $(26 \%$ for each). L3-4 was the most frequently involved level by FJO (18\%), followed by L4-5 914\%) \& L5-S1 (9\%), as shown in Table 1.

Age was significantly associated with the presence of FJO, while gender and female parity were not (table 2). On other hand, higher number of disc levels affected by FJO was seen in older age but with borderline significance ( $p$ value 0.07 ) while no statistically significant association was seen between neither the parity nor the gender of patents with the number of affected level ( $p$ values 0.44 and $p=0.79$ respectively).

TABLE I: OVERALL DESCRIPTIVE STATISTICS FOR THE DEMOGRAPHIC AND OBSERVATIONS OF STUDY PARAMETERS OF THE POPULATION OF THE STUDY

\begin{tabular}{|c|c|}
\hline Parameter & Value \\
\hline $\begin{array}{l}\text { Age (year): } \\
\text { Mean: } \\
\text { Range: }\end{array}$ & $\begin{array}{l}46.62 \pm 13.72 \\
20-90\end{array}$ \\
\hline $\begin{array}{l}\text { Gender: } \\
\text { No. (\%) Males } \\
\text { No. (\%) Females } \\
\text { Male: Female ratio }\end{array}$ & $\begin{array}{l}36(36 \%) \\
64(64 \%) \\
1: 1.77 \\
\end{array}$ \\
\hline BMI: Mean & $30.4 \pm 5.9$ \\
\hline $\begin{array}{l}\text { Parity (out of } 64 \text { women) Median } \\
\text { No. (\%) of women parity } 0-3 \\
\text { No. (\%) of women parity } 4-6 \\
\text { No. }(\%) \text { of women parity }=>7\end{array}$ & $\begin{array}{l}4 \pm 3.5 \\
26(40.6 \%) \\
17(26.56 \%) \\
21(32.81 \%) \\
\end{array}$ \\
\hline Weight $(\mathrm{Kg})$ Mean & $80.21 \pm 3.5$ \\
\hline Height (CM) Mean & $163.4 \pm$ SD 8.7 \\
\hline $\begin{array}{l}\text { Disc degeneration score mean, } \\
\text { (median) } \\
\qquad \begin{array}{l}\text { L3-4 } \\
\text { L4-5 } \\
\text { L5-S1 }\end{array}\end{array}$ & $\begin{array}{l}2.8 \pm 1.3,(3) \\
3.1 \pm 1.2,(3) \\
2.9 \pm 1.5,(3)\end{array}$ \\
\hline $\begin{array}{l}\text { No. (\%) of patients with FJO Total } \\
\text { (out of } 100) \text { : } \\
\text { Single level out of FJO positive (23): } \\
\text { Two levels out of FJO positive (23): } \\
\text { Three levels out of FJO positive (23): }\end{array}$ & $\begin{array}{l}23(23 \%) \\
11(11 \%), 11 / 23(48 \%) \\
6(6 \%), 6 / 23(26 \%) \\
6(6 \%), 6 / 23(26 \%) \\
\end{array}$ \\
\hline $\begin{array}{l}\text { No. }(\%) \text { of patients with FJO } \\
\text { according to the level: L3-4 } \\
\text { L4-5 } \\
\text { L5-S1 }\end{array}$ & $\begin{array}{l}18(18 \%) \\
14(14 \%) \\
9(9 \%)\end{array}$ \\
\hline
\end{tabular}

TABLE II: ASSOCIATION OF AGE, GENDER AND FEMALE PARITY WITH

\begin{tabular}{|c|c|c|c|c|}
\hline \multicolumn{5}{|c|}{ PRESENCE OF FJO. } \\
\hline \multirow[t]{2}{*}{ Parameter } & FJO & FJO & \multirow[t]{2}{*}{ Total } & \multirow[t]{2}{*}{$\mathrm{P}$ values } \\
\hline & $\begin{array}{l}\text { Yes, No. } \\
(\%)\end{array}$ & $\begin{array}{l}\text { NO, } \\
(\%)\end{array}$ & & \\
\hline \multicolumn{4}{|l|}{ Age } & \multirow{4}{*}{$\begin{array}{l}\mathrm{p}=0.018 \\
\text { (Significant) }\end{array}$} \\
\hline $20-39$ & $5(15.63)$ & $27(84.38)$ & 32 & \\
\hline $40-59$ & $8(17.39)$ & $38(82.61)$ & 46 & \\
\hline$>=60$ & $10(45.45)$ & $12(54.55)$ & 22 & \\
\hline \multicolumn{4}{|l|}{ Gender } & \multirow{3}{*}{$\begin{array}{l}\mathbf{p}=\mathbf{0 . 7 9} \\
\text { (not significant) }\end{array}$} \\
\hline Males & $6(16.7)$ & $30(83.3)$ & 36 & \\
\hline Females & $17(26.56)$ & $47(73.44)$ & 64 & \\
\hline \multicolumn{4}{|l|}{ Parity } & \multirow{5}{*}{$\begin{array}{l}\mathbf{p}=\mathbf{0 . 1} \\
\text { (not significant) }\end{array}$} \\
\hline $0-3$ & $4(15.38)$ & $22(84.62)$ & 26 & \\
\hline 4 to 6 & $4(23.53)$ & $13(76.47)$ & 17 & \\
\hline $7=>$ & $9(42.86)$ & $12(57.14)$ & 21 & \\
\hline Total & 17 & 47 & 64 & \\
\hline
\end{tabular}

The degree of DD was significantly associated with presence of FJO at L3/4 \& L4/5 levels but with borderline 
significance at L5/S1 (table 3). However, no statistically significant association was found between the number of levels affected by FJO (single, two or three) with the DD at any of L3-4, L4-5 and L5-S1 levels (p values 0.42, 0.64 and 0.64 respectively).

TABLE III: ASSOCIATION OF AGE, GENDER AND FEMALE PARITY WITH

\begin{tabular}{|c|c|c|c|c|}
\hline \multicolumn{5}{|c|}{ PRESENCE OF FJO. } \\
\hline \multirow[t]{2}{*}{ Grades/Level } & FJO & FJO & \multirow[t]{2}{*}{ Total } & \multirow[t]{2}{*}{$\mathrm{P}$ values } \\
\hline & $\begin{array}{l}\text { Yes, No. } \\
(\%)\end{array}$ & $\begin{array}{l}\text { NO, } \\
(\%)\end{array}$ & & \\
\hline \multicolumn{4}{|l|}{ L3-4 } & \multirow{5}{*}{$\begin{array}{l}\mathrm{P}<0.0001 \\
\text { (Highly } \\
\text { significant) }\end{array}$} \\
\hline $0-1$ & $1(5.56)$ & $17(94.44)$ & 18 & \\
\hline 2 to 3 & $6(11.32)$ & $47(88.68)$ & 53 & \\
\hline 4 to 5 & $16(55.17)$ & $13(44.83)$ & 29 & \\
\hline Total & 23 & 77 & 100 & \\
\hline \multicolumn{4}{|l|}{ L4-5 } & \multirow{5}{*}{$\begin{array}{l}\mathrm{P}=0.04 \\
\text { (Significant) }\end{array}$} \\
\hline $0-1$ & $0(0)$ & $10(100)$ & 10 & \\
\hline 2 to 3 & $8(17.8)$ & $37(82.2)$ & 45 & \\
\hline 4 to 5 & $15(33.3)$ & $30(66.7)$ & 45 & \\
\hline Total & 23 & 77 & 100 & \\
\hline \multicolumn{4}{|l|}{ L5-S1 } & \multirow{5}{*}{$\begin{array}{l}\mathrm{P}=0.057 \\
\text { (Borderline } \\
\text { significant) }\end{array}$} \\
\hline $0-1$ & $1(5.26)$ & $18(94.74)$ & 19 & \\
\hline 2 to 3 & $12(30.77)$ & $27(69.23)$ & 39 & \\
\hline 4 to 5 & $10(17.24)$ & $48(82.76)$ & 58 & \\
\hline Total & 23 & 77 & 100 & \\
\hline
\end{tabular}

Overall, there was no statistically significant difference between patients with and without FJO regarding weight, height or BMI (Table 4). However, among patients with FJO, BMI was significantly correlated with increasing number of levels affected by FJO ( $p$ value 0.037 ), while neither the weight, height nor age were significantly different $(0.98,0.39$ and 0.54 respectively)

TABLE IV: MEAN WEIGHT, HEIGHT AND BMI DIFFERENCE BETWEEN PATIENTS WITH FJO VERSUS WITHOUT FJO

\begin{tabular}{|c|c|c|c|}
\hline Parameter & \multicolumn{2}{|c|}{ Facet joint osteoarthritis } & $P$ values \\
\hline & Yes & No & \\
\hline \multirow{3}{*}{$\begin{array}{l}\text { Weight }(\mathrm{kg}) \\
\text { Mean } \\
\text { Standard deviation }\end{array}$} & & & \multirow[t]{3}{*}{$\mathrm{p}=0.88$} \\
\hline & 79.83 & 80.29 & \\
\hline & 10.41 & 14.39 & \\
\hline \multirow{4}{*}{$\begin{array}{l}\text { Height (CM) } \\
\text { Mean } \\
\text { Standard deviation }\end{array}$} & & & \multirow[t]{4}{*}{$\mathrm{p}=0.6$} \\
\hline & & & \\
\hline & 162.52 & 163.60 & \\
\hline & 9.32 & 8.57 & \\
\hline \multirow{3}{*}{$\begin{array}{l}\text { BMI } \\
\text { Mean } \\
\text { Standard deviation }\end{array}$} & & & \multirow[t]{3}{*}{$\mathrm{p}=0.96$} \\
\hline & 30.46 & 30.39 & \\
\hline & 4.18 & 6.36 & \\
\hline
\end{tabular}

\section{CONCLUSION}

Understanding the factors associated with the one of important but underestimated elements of spinal degenerative disease, the FJO, is an essential step in management of patients with LBP.

The frequency of FJO in our population was $23 \%$ which falls within the reported ranges $[12,15]$.

Among the lower three lumbar levels and contrary to Kalinchman et al [19], FJO was slightly more common at L3-4 than L4-5 (18 vs 14\% respectively) which can be attributed mainly to the hypermobility of these segments and sagittal orientation of their facet joints relative to more stable L5/S1 and more coronal orientation of facet joint at this level [20, 21].
Among the demographic factors that may be associated with presence of FJO, our current study showed that age was significantly associated with the overall prevalence of FJO. This is consistent with findings of other studies [7, 19 and 5]. Moreover, older patients have more levels affected by FJO than younger ones, consolidating the significance of age in the degeneration of facet joints.

BMI was also not significantly associated with prevalence of FJO; however, patients with higher BMI tend to have more levels affected by FJO.

Studies have addressed the role of estrogen-receptor in the process of joint degeneration [22, 23] which supports our finding that female were more frequent affected by FJO (16 vs 7) at all three levels studied in our study. This is in agreement with Kalinchman [19] only at L4/5 levels and in contrary to other studies, which found male predominance [24] or did not found sex difference [19] in the prevalence of FJO.

Importantly, the degree of IVD degeneration seems to have significant impact on the FJO, they may share underlying etiology or may be acting on each other [7,19]. This may also explain why the presence of FJO was associated with the degeneration of the corresponding level and not with number of the overall levels affected.

One of limitations of our study is that we used MRI for the diagnosis of FJO while CT scan is the optimal modality specially regarding the bony elements, however, MRI is the most common and routinely used modality in evaluation of LBP and it showed moderate agreement with CT in assessment of the FJO [3, 4].

In conclusion, age was significantly associated with both higher overall prevalence of FJO and higher number of involved levels. Female were more affected than males and women with advanced multiparity were more affected but without statistical significance. BMI was statistically associated with increasing number of level affected. These demographic factors should be addressed in the pathogenesis of FJO. Moreover, IVD degeneration was also significantly associated with presence of FJO (but not with number of levels), therefore, facet joints should be carefully evaluated by imaging when IVD degeneration is noted on lumbosacral spinal imaging. Finally, future case-control and long-term cohort studies to investigate the possible etiological role of these factors, are still worthy.

\section{REFERENCES}

[1] Deyo RA, Mirza SK, Martin BI. Back pain prevalence and visit rates: estimates from U.S. national surveys, 2002. Spine. Deyo RA, Mirza SK, Turner JA, Martin BI. Overtreating chronic back pain: time to back off? JAm Board Fam Med 2009;22:62e8.

[2] Katz JN. Lumbar disc disorders and low-back pain: socioeconomic factors and consequences. J Bone Joint Surg Am 2006;88(Suppl 2):21e4. 2006;31:2724e7.

[3] Weishaupt D, Zanetti M, Boos N, Hodler J. MR imaging and CT in osteoarthritis of the lumbar facet joints. Skeletal Radiol 1999;28:215e9.

[4] Suri P, Dharamsi AS, Gaviola G, Isaac Z. Association of facet joint bone marrow lesions and other features with low back pain: a pilot study. PM\&R 2013 Mar; 5(3):194:200.

[5] Carrera GF, Williams AL. Current concepts in evaluation of the lumbar facet joints. Crit Rev Diagn Imaging 1984;21:85e104.), 13. Gellhorn AC, Katz JN, Suri P. Osteoarthritis of the spine: the facet joints. Nat Rev Rheumatol 2013 Apr; 9(4): 216e24. 
[6] Manchikanti L, Pampati V, Rivera J, Fellows B, Beyer C, Damron K. Role of facet joints in chronic low back pain in the elderly: a controlled comparative prevalence study. Pain Pract 2001;1:332e7.

[7] Kalichman L, Hunter DJ. Lumbar Facet Joint Osteoarthritis: A Review. Seminars in Arthritis and Rheumatism, 2007 Volume 37, Issue 2, Pages 69-80)

[8] Website:www.radiologyassistant.nl/en/p4bb9e3b74b6a0/spinelumbar-disc herniation.html date of access at December 2018

[9] Kjaer P, Leboeuf-Yde C, Korsholm L, Sorensen JS, Bendix T. Magnetic resonance imaging and low back pain in adults: a diagnostic imaging study of 40-year-old men and women. Spine 2005;30:1173e80.

[10] Savage RA, Whitehouse GH, Roberts N. The relationship between the magnetic resonance imaging appearance of the lumbar spine and low back pain, age and occupation in males. Eur Spine J 1997;6:106e14.

[11] Schwarzer AC, Aprill C, Derby R, et al. Clinical features of patients with pain stemming from the lumbar zygapophyseal joints. Is the lumbar facet syndrome a clinical entity? Spine 1994;10:1132-1137.

[12] Manchkanti L, Pampati V, Fellows B, et al. Prevalence of facet join pain in chronic low back pain. Pain Physician 1999;2:59-64.

[13] Manchikanti L, Pampati RR, Fellows B, et al. The diagnostic validity and therapeutic value of medial branch blocks with or without adjuvants. Curr Rev Pain 2000;4:337-344.

[14] Dreyer SJ, Dreyfuss PH. Low back pain and the zygapophysial (facet) joints. Arch Phys Med Rehabil 1996;77:290-300.

[15] Schwarzer AC, Wang S, Bogduk N, et al. Prevalence and clinical features of lumbar zygapophysial joint pain. A study in an Australian population with chronic low back pain. An Rheum Dis 1995;54:100106.

[16] Schwarzer AC, Wang SC, O'Driscoll D, et al. The ability of computed tomography to identify a painful zygoapophyseal joint in patients with chronic low back pain. Spine 1995;20:907-912.

[17] Dreyfuss PH, Dreyer SJ, Herring SA. Contemporary concepts in spine care. Lumbar zygapophysial (facet) joint injections. Spine 1995;20:2040-2047.

[18] Pfirrmann W. A., Metzdorf A., Zanetti M. ,Hodler J., and Boos N, Magnetic Resonance Classification of Lumbar Intervertebral Disc Degeneration . Spine 2001;26:1873-1878)

[19] Kalichman L, Li L, Kim D, Guermazi A, Berkin V, O’Donnell C. Facet joint osteoarthritis and low back pain in the community based Population. Spine (Phila Pa 1976). 2008 November 1; 33(23): 25602565)

[20] Grobler LJ, Robertson PA, Novomey JE, et al. Etiology of spondylolisthesis. Assessment of the role played by lumbar facet joint morphology. Spine 1993;18:80-91.

[21] Iguchi $\mathrm{T}$, Wakami $\mathrm{T}$, Kurihara $\mathrm{A}$, et al. Lumbar multilevel degenerative spondylolisthesis: radiological evaluation and factors related to anterolisthesis and retrolisthesis. J Spinal Disord Tech 2002;15:93-99.

[22] Ha KY, Chang CH, Kim KW, et al. Expression of estrogen receptor of the facet joints in degenerative spondylolisthesis. Spine 2005;30:562-566.

[23] Fujiwara A, Lim TH, An HS, et al. The effect of disc degeneration and facet joint osteoarthritis on the segmental flexibility of the lumbar spine. Spine 2000;25:3036-3044.

[24] Eubanks JD, Lee MJ, Cassinelli E, et al. Prevalence of lumbar facet arthrosis and its relationship to age, sex, and race: an anatomic study of cadaveric specimens. Spine 2007;32:2058-2062. 